\title{
Efeito do pH e do Tempo de Contato na Adsorção de Corantes Reativos por Microesferas de Quitosana
}

\author{
Irene Y. Kimura, Affonso C. Gonçalves Jr., Joni Stolberg, Mauro C. M. Laranjeira e Valfredo T. de Fávere
}

Resumo: Microesferas de quitosana com grau de reticulação de $24 \%$ foram empregadas para adsorção dos corantes reativos Azul 2, Preto 5 e Laranja 16. A adsorção dos corantes reativos foi avaliada em função da acidez da solução e do tempo de contato com o adsorvente. A constante de velocidade $(\mathrm{k})$ e a capacidade de adsorção aumentaram com a diminuição do $\mathrm{pH}$. Em $\mathrm{pH}>10,0$, a adsorção dos corantes praticamente não ocorre, assim soluções neste $\mathrm{pH}$ podem ser usadas para dessorver os corantes das microesferas. A principal interação é de natureza eletrostática entre os grupos $-\mathrm{NH}_{3}{ }^{+}$da quitosana e $-\mathrm{SO}_{3}{ }^{-}$dos corantes.

Palavras-chave: Microesferas de quitosana, adsorção, corantes reativos

\section{Introdução}

Uma das grandes dificuldades encontradas pelas indústrias têxteis está centrada no problema ambiental, principalmente no controle e remoção dos corantes de efluentes residuários. Os corantes são compostos químicos orgânicos que possuem a propriedade de absorver luz visível seletivamente, razão pela qual aparecem coloridos, devido à presença de grupos cromóforos tais como nitro, nitroso, azo e carbonila. A cor destes compostos é intensificada e/ou modificada por grupos auxocromos tais como etila, nitro, amino, sulfônico, hidroxila, metóxi, etóxi, cloro e bromo. A estabilidade da molécula do corante é diretamente associada à força de ligação química dos átomos componentes dos grupos cromóforos e auxocromos. Um dos aspectos mais importantes dos corantes é a sua durabilidade, ou proprieda- de de permanência sem alteração de sua cor, a isso chamamos de resistência ou solidez à luz ${ }^{[1]}$. Além disso, os grupos auxocromos sulfônicos tornam a molécula do corante solúvel em meio aquoso e aumentam a afinidade pelas fibras no processo de tingimento. Suas concentrações podem ser menores que $1 \mathrm{ppm}$, isto é, inferiores a outros compostos químicos em águas residuárias e, mesmo assim, serão detectáveis por método espectrofotométrico.

Os corantes reativos constituem uma classe de corantes que vêm sendo utilizados em escala crescente pelas indústrias têxteis devido à sua reatividade com as fibras e estabilidade da cor. A molécula do corante reativo pode ser definida pelos seguintes sistemas estruturais: sistema cromofórico, que é parte responsável pela fenômeno da cor; um grupo sulfonato, responsável pela solubilidade e caráter aniônico do corante; e

Irene Y. Kimura, Departamento de Química, Universidade Estadual de Maringá (UEM), Av. Colombo n 5790, CEP: 87020-900, Maringá - PR; Affonso C. Gonçalves Jr., Joni Stolberg, Mauro C. M. Laranjeira e Valfredo T. de Fávere*, Grupo de Pesquisa em Quitinas e Aplicações Tecnológicas (QUITECH), Departamento de Química, Universidade Federal de Santa Catarina (UFSC), CP 476, CEP: 88040-900 - Trindade - Florianópolis - SC. 
um grupo reativo, que pode formar uma ligação covalente com as fibras de celulose por reações de adição ou substituição nucleofílica. Os grupos reativos mais comuns são do tipo anel heterocíclico e vinilsulfona ${ }^{[2,3]}$. Um exemplo de reação de adição nucleofílica entre o corante-celulose é representada pelas equações abaixo:

$$
\begin{aligned}
& \text { Corante- } \mathrm{SO}_{2} \mathrm{CH}_{2} \mathrm{CH}_{2} \mathrm{OSO}_{3} \mathrm{Na}+\mathrm{NaOH} \rightarrow \\
& \text { Corante- } \mathrm{SO}_{2} \mathrm{CH}^{2}=\mathrm{CH}_{2}+\mathrm{Na}_{2} \mathrm{SO}_{4}+\mathrm{H}_{2} \mathrm{O} \\
& \text { Corante- } \mathrm{SO}_{2} \mathrm{CH}=\mathrm{CH}_{2}+\text { HO-Celulose } \rightarrow \\
& \text { Corante- } \mathrm{SO}_{2} \mathrm{CH}_{2}-\mathrm{CH}_{2}-\mathrm{O} \text {-Celulose }
\end{aligned}
$$

onde o grupo reativo é o vinilsulfona (- $\mathrm{SO}_{2} \mathrm{CH}=\mathrm{CH}_{2}$ ) e reage preferencialmente com o grupo hidroxila do carbono seis da celulose.

A remoção de corantes de efluentes têxteis por adsorção tem sido relatada em vários trabalhos ${ }^{[4-9]}$. A grande vantagem deste processo é a possibilidade de recuperação do corante na forma concentrada e a reutilização do adsorvente no processo. Uma variedade de adsorventes tem sido empregada, destacando-se carvão ativo ${ }^{[10-12]}$, turfa ${ }^{[12,13]}$, sílica ${ }^{[12,14]}$, alumina $^{[12]}$, celulose $\mathrm{e}^{[15,16]} \mathrm{e}$, mais recentemente, quitina e quitosana ${ }^{[4-9,15-17]}$.

Yoshida et al[17]. estudaram a adsorção de corante ácido alaranjado II sobre fibras de quitosana reticuladas. Em $\mathrm{pH} \leq 4,0$ foi observado que a capacidade de saturação da fibra era próxima da concentração de grupos amino do polímero.

Kim et al. ${ }^{[8]}$ relataram o efeito do grau de desacetilação da quitina na adsorção de quatro corantes, ácido azul 193, ácido azul 40, direto amarelo 44 e azul direto 78. A quitina foi preparada com grau de desacetilação variando de $10,7 \%$ a $67,2 \%$, sendo que as amostras com grau de desacetilação de $36,30 \%$ e 46,86\% foram as mais efetivas na remoção em $\mathrm{pH}=3,0$ e $\mathrm{pH}=4,0$. As quitinas com 46,8 \% e 67,2 \% eram dissolvidas parcialmente em solventes aquosos ácidos.

Longhinotti e colaboradores ${ }^{[9]}$ investigaram a adsorção de corantes aniônicos alaranjado G, alaranjado IV e alaranjado de xilenol pela quitina empregando a isoterma de Langmuir. Os resultados revelaram que a capacidade de adsorção era maior em meio ácido e que a principal interação com o adsorvente era de natureza eletrostática.

A quitosana é um biopolímero obtido a partir da hidrólise alcalina dos grupos acetamida da quitina, que tem mostrado ser um excelente adsorvente para corantes aniônicos. No entanto, o uso deste biopolímero num efluente ácido limita a remoção de corantes devido a sua tendência de solubilização. Soluções aquosas ácidas protonam os grupos $\mathrm{NH}_{2}$ da cadeia polimérica, produzindo um policátion e a mútua repulsão entre cadeias do policátion, determinam a dissolução do polímero.

O propósito deste trabalho foi preparar microesferas de quitosana reticulada com glutaraldeído, resultante da formação de ligações covalentes entre grupos amino das cadeias do polímero e as funções aldeído do agente de reticulação. Esta modificação no polímero faz com que a solubilidade da quitosana diminua acentuadamente, aumentando o potencial de utilização do polímero no estudo da dependência do $\mathrm{pH}$ e do tempo de contato na adsorção dos corantes reativos Azul 2, Preto 5 e Laranja 16.

\section{Experimental}

\section{Materiais e Métodos}

Reativo Azul 2 (Procion Blue HB, grau de pureza $60 \%$ ), Reativo Preto 5 (Remazol Black 5, grau de pureza $55 \%$ ) e Reativo Laranja 16 (Remazol Brilliant Orange 3R, grau de pureza $50 \%$ ) foram obtidos da Aldrich Chemical Company, Inc. e utilizados sem purificações prévias, tendo em vista que estes corantes são utilizados nas indústrias têxteis na forma comercial. A figura 1 ilustra a estrutura dos corantes reativos empregados neste trabalho com as respectivas unidades que compõem as moléculas ${ }^{[18-19]}$.

\section{Obtenção de Quitina}

As cascas de camarão secas e trituradas (220g) foram imersas em 2,0 L de $\mathrm{HCl} 2,0 \mathrm{~mol} / \mathrm{L}$, durante 5 horas a temperatura ambiente para eliminação dos sais de cálcio. $\mathrm{O}$ material foi então lavado, seco e novamente imerso em $500 \mathrm{~mL}$ de $\mathrm{HCl}$ 2,0 $\mathrm{mol} / \mathrm{L}$ por 48 horas com agitação. Para eliminação das proteínas o material foi colocado em contato com $500 \mathrm{~mL}$ de $\mathrm{NaOH} 1,0 \mathrm{~mol} / \mathrm{L}$ durante 12 horas a $100^{\circ} \mathrm{C}$, sob refluxo. A extração com álcali foi repetida por mais duas vezes e finalmente o material foi lavado sequencialmente com água até meio neutro, etanol para eliminação dos pigmentos e éter etílico, e posteriormente seco a $60^{\circ} \mathrm{C}^{[20]}$. 

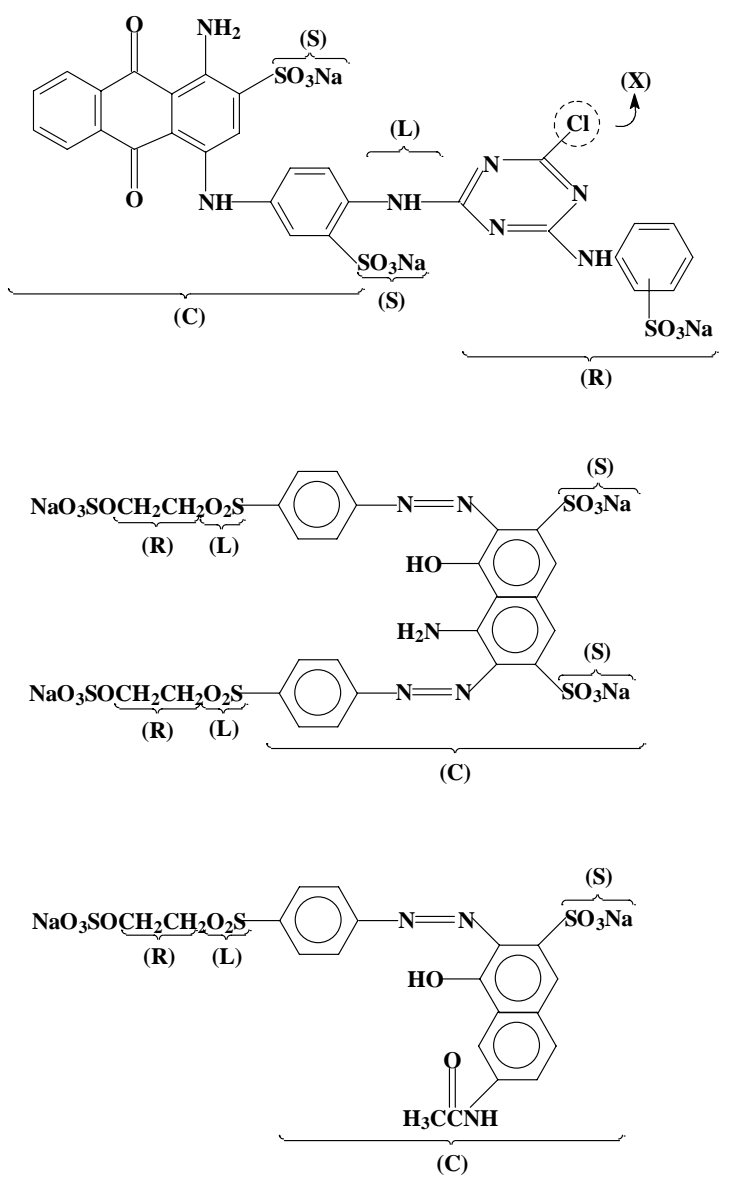

C: Grupo Cromóforo

S: Grupo de Solubilização

R: Grupo Reativo

X: Grupo de Saída

Figura 1. Estrutura dos corantes reativos: (1) Azul 2, (2) Preto 5 e (3) Laranja 16.

\section{Obtenção de Quitosana}

A quitina $(10,0 \mathrm{~g})$ foi submetida à reação de desacetilação pelo método de Broussignac ${ }^{[21]}$. A quitosana obtida foi purificada, por dissolução em ácido acético $3 \%(\mathrm{~m} / \mathrm{v})$ e filtração através de cadinho sinterizado com porosidade média para eliminação de algum resíduo insolúvel. O material dissolvido foi seco num Mini Spray Dryer (Büchi modelo B-191), obtendo-se partículas de aproximadamente $25 \mu \mathrm{m}$.

O grau médio de desacetilação $(\% \overline{\mathrm{GD}})$ foi determinado por titulação condutimétrica, empregando um condutivímetro Micronal (modelo B330) e um titulador automático Schott Geräte (modelo T 80/20). Uma amostra de $200 \mathrm{mg}$ de quitosana foi transferida para um béquer de $600 \mathrm{~mL}$, contendo $450 \mathrm{~mL}$ de solução $\mathrm{NaCl}$ 0,001 mol/L, 5,0 mL de $\mathrm{HCl}$ 1,0 $\mathrm{mol} / \mathrm{L}$ e, após a dissolução do polímero, a titulação foi conduzida com adição de $0,5 \mathrm{~mL}$ de $\mathrm{NaOH}$ $0,100 \mathrm{~mol} / \mathrm{L}$ a cada 20 segundos, sob atmosfera de nitrogênio ${ }^{[22]}$.

\section{Preparação das Microesferas de Quitosana}

A quitosana $(2,5 \mathrm{~g})$ foi dissolvida em $100 \mathrm{~mL}$ de ácido acético $5 \%(\mathrm{~m} / \mathrm{v})$. A solução viscosa obtida foi gotejada com auxílio de uma bomba peristáltica (Ismatec) sobre um banho contendo solução de $\mathrm{NaOH} 2,0 \mathrm{~mol} / \mathrm{L}$. As microesferas gelificadas foram lavadas com água destilada até meio neutro e colocadas em contato com uma solução de glutaraldeído $2,5 \%(\mathrm{~m} / \mathrm{v})$ para a reticulação, sendo utilizada a relação de $1,5 \mathrm{~mL}$ de solução de glutaraldeído por grama de microesferas gelificadas e a mistura foi mantida durante 24 horas sob temperatura ambiente ${ }^{[23]}$. O material foi lavado com água destilada para retirar o excesso do agente reticulante. Posteriormente, as microesferas foram deixadas em contato com acetona durante 24 horas para facilitar a eliminação de água e secas a temperatura ambiente.

\section{Caracterização das Microesferas de Quitosana}

Após a secagem, as microesferas foram caracterizadas para a determinação do tamanho médio das partículas, porosidade e grau de reticulação. O tamanho das partículas foi determinado empregando-se um microscópio eletrônico de varredura (Philips modelo XL30). As amostras foram colocadas em estabes; recobertas com ouro, micrografadas e analisadas através da microsonda de energia dispersiva de raios $\mathrm{X}(\mathrm{EDX})$. A análise de porosimetria foi realizada a partir da medida da distribuição de poros da microesfera de quitosana, empregando o aparelho Poresizer 9320 (Micrometrics) e o grau de reticulação por titulação ácido-base pelo método indireto.

Dependência de adsorção dos corantes com o pH e o tempo de contato

Amostras de microesferas de quitosana ( $100 \mathrm{mg}$ ou $0,298 \mathrm{mmol}$ de grupos $\mathrm{NH}_{2}$ ) foram colocadas em contato com soluções individuais dos corantes reativos: Reativo Azul $2\left(\mathrm{C}_{\mathrm{o}}=70,0 \mathrm{mg} / \mathrm{L}\right.$ ou 
$\left.5,83 \times 10^{-3} \mathrm{mmol}\right)$, Reativo Preto $5 \quad\left(\mathrm{C}_{\mathrm{o}}=70,0 \mathrm{mg} / \mathrm{L}\right.$ ou $\left.4,94 \times 10^{-3} \mathrm{mmol}\right)$ e Reativo laranja 16 $\left(\mathrm{C}_{\mathrm{o}}=70,0 \mathrm{mg} / \mathrm{L}\right.$ ou $\left.7,93 \times 10^{-3} \mathrm{mmol}\right)$, mantendo a força iônica constante $(\mu=0,100 \mathrm{~mol} / \mathrm{L}) . \mathrm{O} \mathrm{pH}$ das soluções foi ajustado com vários tampões, que posteriormente, foram transferidos para uma plataforma agitadora a $25,0 \pm 0,5^{\circ} \mathrm{C}$ e agitadas a 150 $\mathrm{rpm}$. Alíquotas de 3,0 $\mathrm{mL}$ foram retiradas em diferentes intervalos de tempo e as concentrações dos corantes nas soluções foram determinadas por espectrofotometria UV-Visível, empregando uma curva analítica para cada corante nos $\lambda_{\text {max. }}=618 \mathrm{~nm}$ (Reativo Azul 2), $\lambda_{\max }=599 \mathrm{~nm}$ (Reativo Preto 5) e $\lambda_{\max }=490 \mathrm{~nm}$ (Reativo Laranja 16).

\section{Resultados e Discussão}

O grau médio de desacetilação $(\overline{\mathrm{GD}})$ de $72,5 \%$ (4,5 mmol de grupos amino/g quitosana) foi calculado a partir da média de três titulações condutimétricas da quitosana.

As microesferas de quitosana foram preparadas pelo método de inversão de fases com $\mathrm{NaOH}$ e reticuladas com glutaraldeído para evitar a solubilização do polímero em soluções de $\mathrm{pH}<4,0$.

A partir da micrografia da microesfera e dos detalhes morfológicos da superfície, foi possível distinguir uma microesfera pouco porosa. $\mathrm{O}$ diâmetro médio de 1,03 $\pm 0,06 \mathrm{~mm}$ foi determinado a partir da micrografia de vinte microesferas, através dos diâmetros dos eixos vertical e horizontal de cada microesfera. A análise por porosimetria de mercúrio revelou que a maioria dos poros apresentou diâmetro inferior a $60 \AA$.

O grau de reticulação de $24 \%$ foi determinado a partir do conteúdo de grupos amino livres por titulação ácido-base, deixando o material em contato com uma solução ácida durante 24 horas para protonação

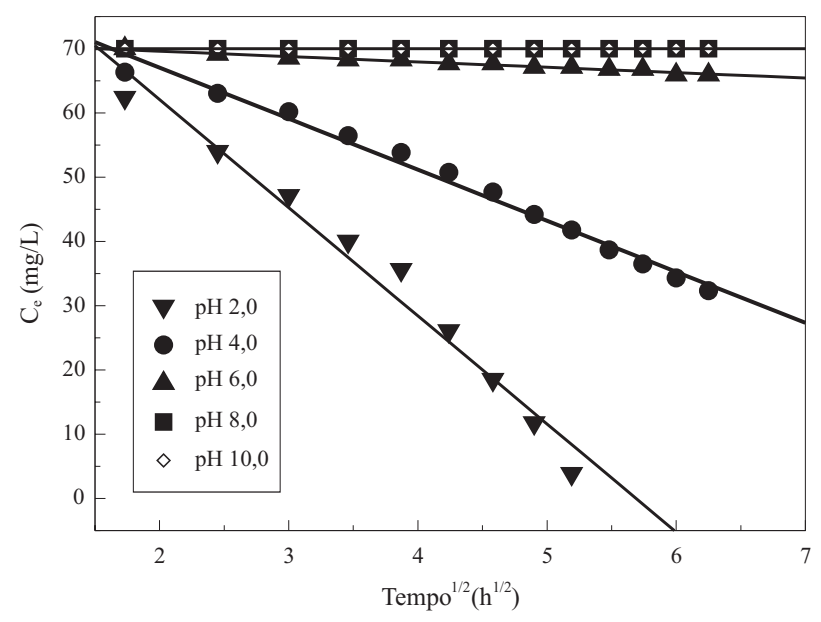

Figura 2. Velocidade de adsorção do corante Reativo Preto 5 pelas microesferas de quitosana em função de $t^{1 / 2}$.

dos grupos amino do polímero. O excesso de ácido foi titulado com solução padrão de $\mathrm{NaOH}$, após as microesferas serem retiradas da solução.

O mecanismo cinético postulado destaca como etapa determinante de velocidade a adsorção do adsorbato sobre adsorvente poroso, sendo esta etapa controlada pela velocidade de difusão intrapartícula nos poros da quitosana. Uma abordagem simples para o tratamento deste mecanismo é proposto onde a concentração de adsorção varia proporcionalmente com o tempo elevado à potência $1 / 2$ $\left(\mathrm{t}^{1 / 2}\right)$, na qual $\mathrm{t}^{1 / 2}$ é o tempo requerido para $\mathrm{o}$ adsorvente adsorver metade da quantidade máxima de adsorbato no equilíbrio ${ }^{[24]}$. Considerando que o equilíbrio da adsorção é lento para ser atingido, a equação 3 pode ser aplicada na sua forma simplificada para este processo cinético controlado por difusão.

$$
\mathrm{C}_{\mathrm{e}}=\mathrm{kt}^{1 / 2}
$$

onde $\mathrm{C}_{\mathrm{e}}$ é a concentração de equilíbrio no tempo $\mathrm{t}$ em miligrama de corante por litro de solução e k é constante de velocidade de adsorção em miligrama de corante por grama de adsorvente e por (hora) ${ }^{1 / 2}$.

Tabela 1. Constantes de velocidade de adsorção dos corantes reativos pelas microesferas de quitosana

\begin{tabular}{|c|c|c|c|c|c|c|}
\hline \multirow[b]{2}{*}{ pH } & \multicolumn{2}{|c|}{ Reativo Azul 2} & \multicolumn{2}{|c|}{ Reativo Preto 5} & \multicolumn{2}{|c|}{ Reativo Laranja 16} \\
\hline & $K\left(m g \cdot g^{-1} \cdot h^{-1 / 2}\right)$ & $\begin{array}{c}\text { Coef. de } \\
\text { Correlação }\end{array}$ & $K\left(\mathrm{mg} \cdot \mathrm{g}^{-1} \cdot \mathbf{h}^{-1 / 2}\right)$ & $\begin{array}{c}\text { Coef. de } \\
\text { Correlação }\end{array}$ & $K\left(\mathbf{m g} \cdot g^{-1} \cdot \mathbf{h}^{-1 / 2}\right)$ & $\begin{array}{c}\text { Coef. de } \\
\text { Correlação }\end{array}$ \\
\hline 2,0 & 7,16 & 0,985 & 16,49 & 0,986 & 15,34 & 0,993 \\
\hline 4,0 & 3,19 & 0,973 & 6,69 & 0,974 & 10,45 & 0,994 \\
\hline 6,0 & 0,70 & 0,938 & 0,81 & 0,985 & 2,83 & 0,991 \\
\hline 8,0 & 0,91 & 0,974 & 0,00 & 1,000 & 1,09 & 0,972 \\
\hline 10,0 & 0,40 & 0,863 & 0,00 & 1,000 & 0,27 & 0,863 \\
\hline
\end{tabular}




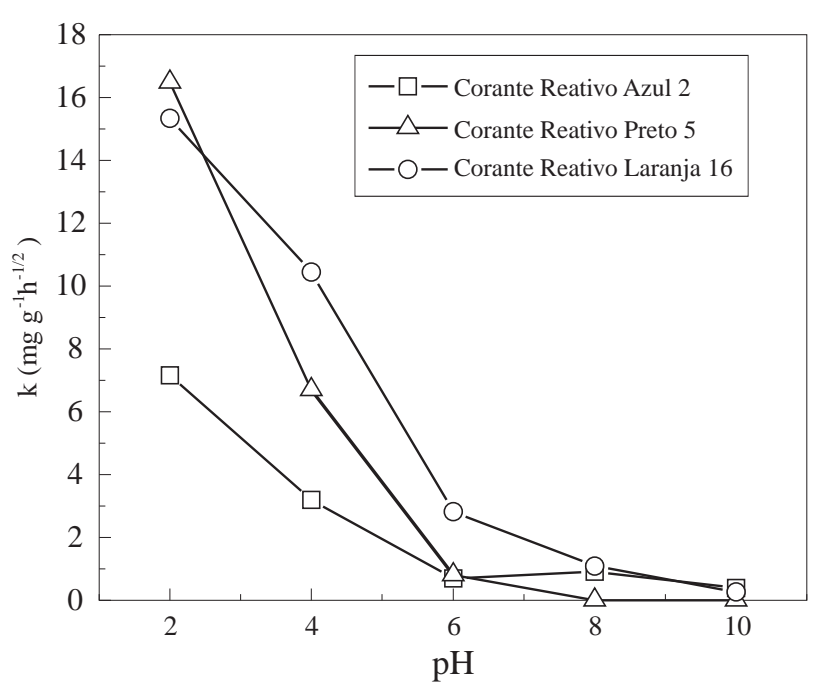

Figura 3. Constantes de velocidade de adsorção em função do $\mathrm{pH}$.

A figura 2 ilustra o gráfico de velocidade de adsorção em função de $t^{1 / 2}$ para o corante Reativo Preto 5 e a tabela 1 mostra os valores de constantes de velocidade obtidos a partir das curvas cinéticas.

O gráfico da concentração de equilíbrio em função de $\mathrm{t}^{1 / 2}$, fornece uma relação linear e a constante de velocidade $(\mathrm{k})$ pode ser determinada a partir do coeficiente angular da reta. A relação linear encon- trada indica que a difusão intrapartícula é a etapa determinante de velocidade. Estes valores podem ser mais úteis do que os dados de adsorção de equilíbrio, visto que os equilíbrios são raramente alcançados na prática ${ }^{[8]}$. A variação da constante de velocidade de adsorção (k) em função do $\mathrm{pH}$ é ilustrada na figura 3. Para os três corantes reativos, a constante de velocidade aumenta com a diminuição do $\mathrm{pH}$ da solução. $\mathrm{O}$ valor de $\mathrm{k}$ é muito maior em meio ácido; e a partir do $\mathrm{pH}$ 10,0 os valores de $\mathrm{k}$ são muito pequenos e, praticamente não ocorre a adsorção dos corantes pelo adsorvente. As curvas relativas ao estudo da dependência das constantes de velocidade de adsorção com o pH das soluções dos corantes apresentam duas partes lineares com diferentes inclinações. No intervalo de $\mathrm{pH}$ de $2,0 \mathrm{a}$ aproximadamente 6,0 as interações são de natureza eletrostática entre os sítios adsorventes $\mathrm{NH}_{3}{ }^{+}$e grupos aniônicos dos corantes. Acima de pH 6,0 a adsorção é praticamente independente do $\mathrm{pH}$ e, sendo atribuída a um processo apenas difusional.

A figura 4 ilustra as isotermas de adsorção em função dos parâmetros $\mathrm{pH}$, tempo de contato e capacidade de adsorção. Em pH 2,0, os corantes apre-



(A)

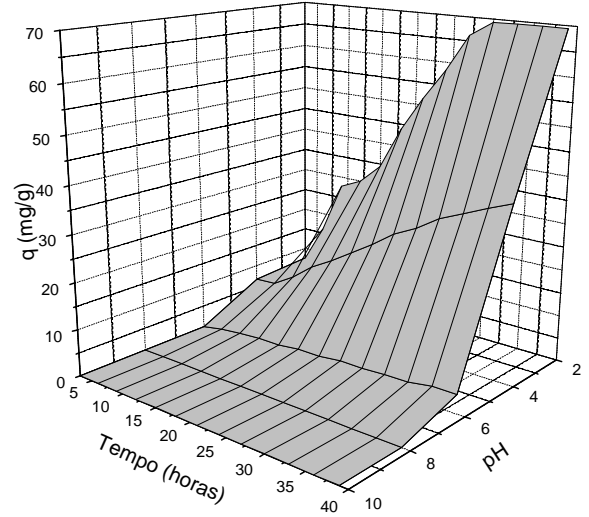

(B)

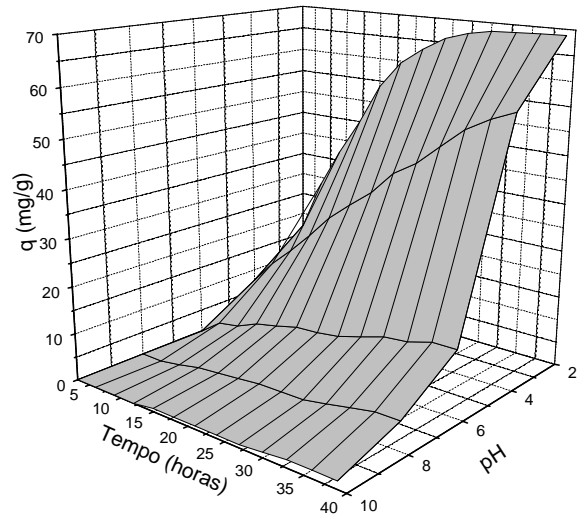

(C)

Figura 4. Dependência do $\mathrm{pH}$ e tempo de contato na adsorção dos corantes reativos pela quitosana. $100 \mathrm{mg}$ microesferas de quitosana, $\mathrm{T}=25,0 \pm 0,5^{\circ} \mathrm{C}, \mu=0,100 \mathrm{~mol} / \mathrm{L}, \mathrm{C}_{\mathrm{o}}=70 \mathrm{mg} / \mathrm{L}$. (A) corante Reativo Azul 2; (B) corante Reativo Preto 5 e (C) corante Reativo Laranja 16. 
sentaram uma maior capacidade de adsorção, sendo que, nesta condição, os corantes Preto 5 e Laranja 16 alcançaram um equilíbrio de adsorção em aproximadamente 24 horas, capacidade em torno de $70 \mathrm{mg} / \mathrm{g}$ e comportamento tipo isoterma de Langmuir. Analisando os gráficos, pode-se concluir que a adsorção em meio ácido dos corantes Preto 5 e Laranja 16 é atribuída, principalmente, às interações iônicas entre os grupos $-\mathrm{SO}_{3}^{-}$dos corantes e $-\mathrm{NH}_{3}{ }^{+}$da quitosana. Portanto, a acidez do meio é um fator importante, influenciando as interações entre adsorvente e adorbato no que diz respeito a interações eletrostáticas. Em relação à porosidade das microesferas, o meio ácido induz uma forte repulsão entre as cadeias de quitosana carregadas positivamente, resultando na expansão dos poros e favorecendo o processo de adsorção. A diminuição da adsorção em meio alcalino justifica-se pela redução no número de grupos $-\mathrm{NH}_{3}{ }^{+}$da quitosana, diminuindo assim a interação entre estes e os grupos $-\mathrm{SO}_{3}^{-}$dos corantes; portanto em $\mathrm{pH}=10,0$ praticamente não ocorreu adsorção dos corantes. Um comportamento diferente foi observado para o corante Azul 2, o sistema não alcançou a condição de equilíbrio após 36 horas de contato, e uma relação linear foi obtida, indicando pouca interação com o adsorvente. Esta relação linear foi observada em toda a faixa de $\mathrm{pH}$ estudado. Isto pode ser atribuído à geometria do corante azul 2, pois nesse caso os grupos sulfonatos estão muito próximos dos grupos amino no próprio corante, sugerindo uma interação intramolecular em meio ácido e impedindo, assim, a interação corante-polímero. Algumas relações lineares foram também reportadas em estudos de Bird e Harris ${ }^{[25]}$, Gonzales-Davila et al. ${ }^{[26]}$, Longhinotti e colaboradores ${ }^{[9]}$, sendo estas isotermas classificadas como isotermas de Nernst.

Este estudo foi conduzido com excesso de polímero em relação aos corantes. Amostras de $100 \mathrm{mg}$ de microesferas de quitosana contêm 0,298 mmol de grupos amino e um volume de $70 \mathrm{~mL}$ de solução de corante $(70 \mathrm{mg} / \mathrm{L})$ contem 5,83.10-3 mmol (Azul 2), 4,94.10 $0^{-3} \mathrm{mmol}$ (Preto 5) e 7,93.10-3 mmol (Laranja 16). A baixa capacidade de saturação dos sítios amino em torno de 70 miligramas de corante por grama de suporte adsorvente ocorreu em função da baixa porosidade das microesferas e provavelmente a obstrução dos poros das microesferas pelas moléculas dos corantes.

\section{Conclusões}

Neste estudo, foi observado que as microesferas de quitosana foram mais efetivas na adsorção dos corantes reativos em meio ácido devido à protonação dos grupos amino estarem cationizados, sendo este o seu principal sítio de adsorção. Em meio alcalino, a diminuição da capacidade de adsorção é atribuída à redução dos grupos $-\mathrm{NH}_{3}{ }^{+}$. Em $\mathrm{pH}>10,0$, a adsorção dos corantes é muito pequena e proporciona um meio altamente efetivo para dessorver os corantes das miscroesferas.

Este novo adsorvente (quitosana reticulada) apresentou uma capacidade inferior à quitosana na forma de pequenas partículas em função da diminuição da área superficial e comprometimento dos grupos amino na reticulação e baixa porosidade. No entanto, este suporte pode ser empregado em sistemas estáticos e dinâmicos de adsorção, possui estabilidade em meio ácido e pode ser empregado em efluentes têxteis ácidos.

\section{Agradecimentos}

Agradecemos à CAPES - PICD e à Universidade Estadual de Maringá - UEM.

\section{Referências Bibliográficas}

1. Salem, V. - Revista Química Têxtil, 38, p.6 (1995).

2. Zollinger, H. - "Color Chemistry: Syntheses, properties and applications of organic dyes and pigments", VCH Publishers, Inc., 2 Ed., New York (1991).

3. Aspland, J.R. - Textile Chemist and Colorist, 24, 5, p.31 (1992).

4. McKay, G.; Blair, H. S.; Gardner, J. R. - J. Appl. Polym. Sci, 27, p. 3043 (1982).

5. Smith, B.; Koonce, T.; Hudson, S.- Am. Dyest. Rep., 82, 10, p.18 (1993).

6. Laszlo, J. A.- Am. Dyest. Rep, 83, 8, p.17 (1994).

7. Longhinotti, E.; Furlan, L.; Laranjeira, M. C. M.; Fávere, V.T.- Química Nova, 19, p. 221 (1997). 
8. Kim, Y. C.; Choi, H.-M.; Cho, H.T.- J. Appl. Polym. Sci, 63, p. 725 (1997).

9. Longhinotti, E.; Pozza, F.; Furlan, L.; Sanchez, M.N.M.; Laranjeira, M.C.M.; Fávere, V.T.- J. Braz. Chem. Soc., 9, 5, p. 435 (1998).

10. Johnston, W.A.- Chem. Eng., 79, 6, p. 87 (1972).

11. Luckchis, G. M.- Chem. Eng, 80, 16, p. 83 (1973).

12. Mckay, G.- Am. Dyest. Rep., 86, 4, p. 29 (1979).

13. Poots, V.J.P.; Mckay, G.; Healy, J.J.- Water Research, 10, p. 1067 (1976).

14. Mckay, G.; Alexander, F.- The Chemical Engineer, 319, p. 243 (1977).

15. Nawar, S.S.; Doma, H.S.- Sci. of the Total Environment. 79, p. 271 (1989).

16. Laszlo, J.A.- Textile Chemist and Colorist, 27, 4, p. 25 (1995).

17. Yoshida, H; Okamoto, A.; Kataoka, T.- Chem. Eng. Sci., 48, p. 2267 (1993).
18. "Colour Index, Society of Dyers and Colourist and American Association of Textile Chemists and Colourists", V. 1-5, USA (1971).

19. "Catalog Handbook of Fine Chemicals", Aldrich Chemical Company, Inc.; USA (1990-1991).

20. Hackman, R. H.- Aust. J. Biol. Sci., 8, p. 530 (1955).

21. Broussignac, J.- Chim. Ind. Gén. Chim., 99, 9, p. 124 (1970).

22. Raymond, L.; Morin, F. G.; Marchessault, R. H.- Carbohydr. Res., 246, p. 331 (1993).

23. Rorrer, L. G.; Hsien, T. Y.; Way, J. D.- Ind. Eng. Chem. Res., 32, p. 2170 (1993).

24. Weber, J. W.; Asce, A. M.; Morris, J. C. - J. Sanit. Eng. Div., p. 31 (1963).

25. Bird, C.L.; Harris, P.J.- Soc. Dyers Col., 73, p.199 (1957).

26. Gonzales-Davila, M.; Santana-Casiano; Mellero, F. J. - J. Colloid Interface Sci., 137, p. 102 (1990).

Recebido: 22/03/99

Aprovado: 03/09/99 